\title{
HEALTH LITERACY STUDY OF PARENTS IN PEDIATRIC EMERGENCY DEPARTMENT
}

\author{
Sigita Burokienè, Aistè Pilkienè; Vilnius University, Faculty of medicine, Clinic of \\ Children's diseases, Lithuania.
}

\section{Background and aims}

Health Literacy (HL) is defined as cognitive and social skills which determine the motivation and ability of individuals to gain access to, understand and use information in ways which promote and maintain good health. HL level of parents here have never been academically researched. The aim of this study is to assess parents $\mathrm{HL}$ level in the PED in Lithuania.

\section{Methods}

Anonymous survey has been carried out in order to perform a cross-sectional study. Research population was parents who visited tertiary-level teaching hospital PED in 8-23 March, 2018 (sample size = 210). HL was assessed with HLS-EU-Q16 and The Newest vital sign (NVS) questionnaires. The HL index (according to replies to HLSEU-Q16 questionnaire) was categorized: Inadequate HL (025), Problematic HL (26-33), Sufficient HL (34-42), Excellent HL (43-50). Functional health literacy (NVS) was measured by asking six questions related to food nutritional fact label. Scoring ratings ranged from 0-6 points, which can be grouped into and adequate (5-6), possibility of limited literacy (3-4), limited literacy level (0-2). Statistical analysis was performed using Rx64 3.1.1 and MS Excel 2013.

\section{Results}

$57 \%$ of parents have adequate literacy, $23 \%$ have the possibility of limited literacy, 19\% limited literacy according NVS (Figure1.).

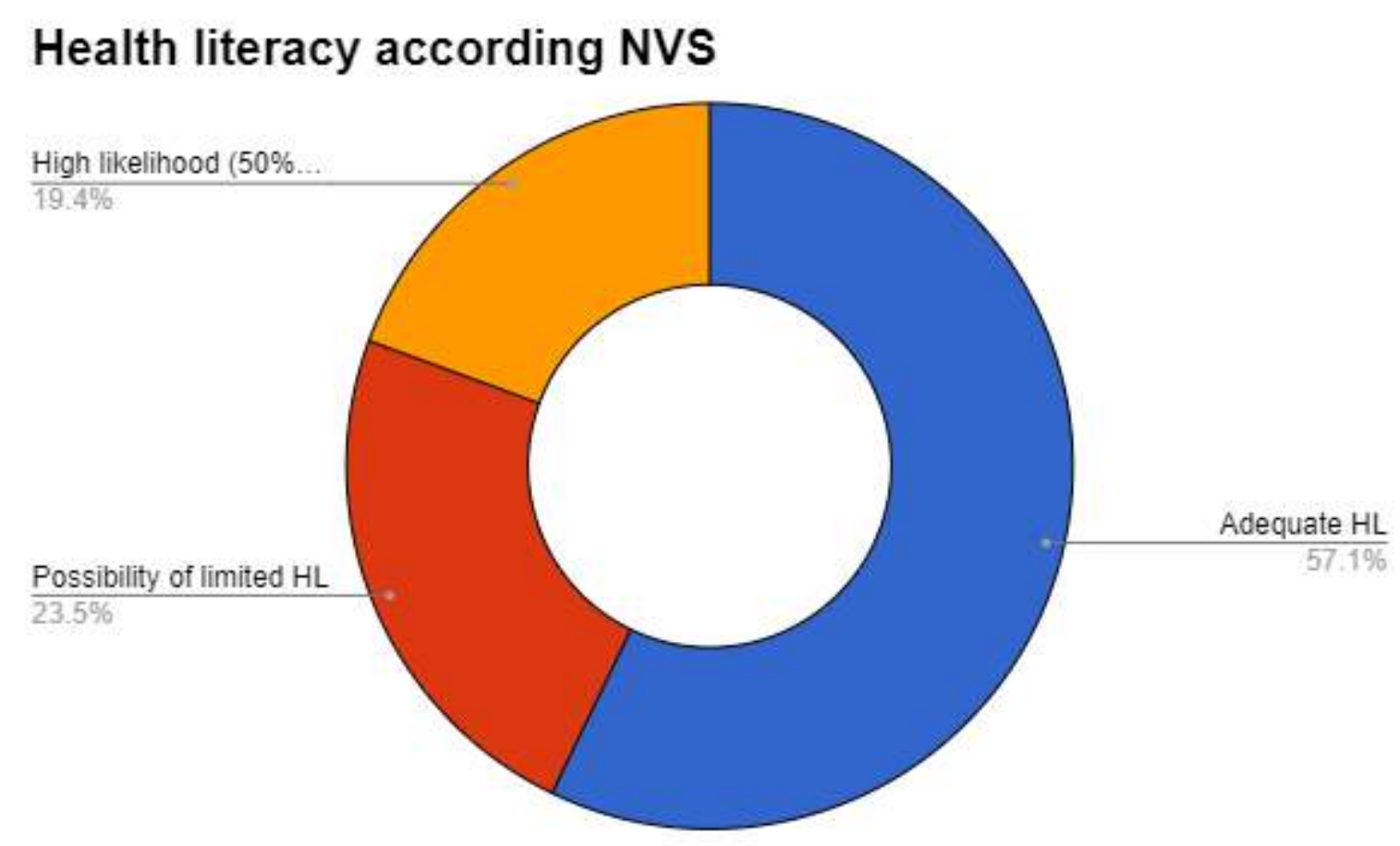

Figure 1. Health literacy according NVS
$4 \%$ of parents have excellent $\mathrm{HL}, 33 \%$ sufficient, $57 \%$ problematic and 5\% inadequate according HLS-EU-Q16 questionnaire (Figure 2.).

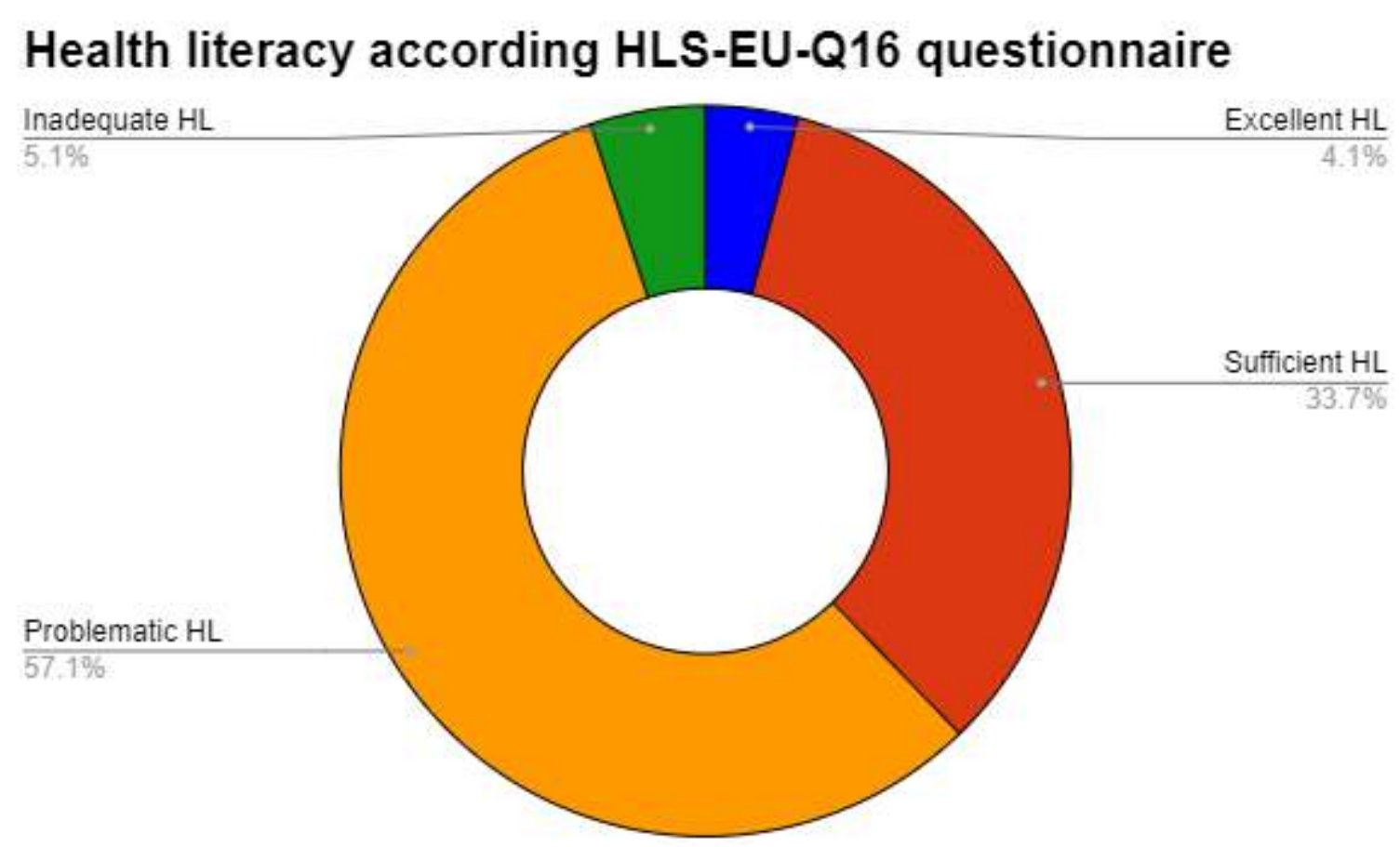

Figure 2. Health literacy according HLS-EU-Q16

Parents with higher education have more adequate functional $\mathrm{HL}(r=0.34, p$-value 0.0001). There was no significant association with limited functional health literacy and gender, age and body mass index (Table 1.).

\begin{tabular}{|lll|}
\hline Variable & $\mathbf{r}$ & p-value* $^{*}$ \\
\hline Gender & 0.03 & 0,655 \\
\hline Age & -0.08 & 0.309 \\
\hline Education & $\mathbf{0 . 3 4}$ & $\mathbf{0 . 0 0 0 1}$ \\
\hline Body mass index & 0.02 & 0,814 \\
\hline
\end{tabular}

${ }^{*}$ P-value from Spearman test

Table 1. Correlation with Functional HL (NVS)

\section{Conclusions}

A large proportion of parents have limited HL skills. The research revealed that parents with higher education have more adequate HL. The results underline the need for improved health education and applying adequate health communication techniques that would enhance understanding among parents with low HL. 